\title{
On the predictive power of CAPE or Shiller's PE ratio: the case of the Greek stock market
}

\section{Dimitrios Kenourgios $^{1} \cdot$ Spyros Papathanasiou $^{2} \cdot$ Anastasia Christina Bampili $^{3}$}

Received: 29 January 2021 / Revised: 25 May 2021 / Accepted: 21 June 2021 /

Published online: 24 July 2021

(c) The Author(s), under exclusive licence to Springer-Verlag GmbH Germany, part of Springer Nature 2021

\begin{abstract}
This paper examines the capability of the Cyclically Adjusted Price to Earnings (CAPE) or Shiller's P/E ratio, along with other relative valuation ratios such as the $\mathrm{P} / \mathrm{E}$ and the P/BV, to predict future returns of the FTSE/ASE Large Cap Index, starting from the development of the index (1997) to December 2018. We have herein used several regression models in order to examine the relationship between the above ratios and the future returns of $1,3,5$ and 10 years. We show that, while P/E and $\mathrm{P} / \mathrm{BV}$ ratios are not correlated to future returns, the CAPE ratio and its variation CAPE 5, which uses real 5 year earnings, are efficient estimators of future returns. Our results imply the informational inefficiency of the Greek Stock Market.
\end{abstract}

Keywords Returns forecasting · FTSE/ASE large cap index - CAPE ratio · Efficient market hypothesis

Spyros Papathanasiou

spapathan@econ.uoa.gr

Dimitrios Kenourgios

dkenourg@econ.uoa.gr

Anastasia Christina Bampili

naur_eowin@hotmail.com

1 Department of Economics, School of Economics and Political Sciences, UoA for Financial Studies, National and Kapodistrian University of Athens, 1 Sofokleous Street, 10559 Athens, Greece

2 Department of Economics, School of Economics and Political Sciences, National and Kapodistrian University of Athens, 1 Sofokleous Street, 10559 Athens, Greece

3 Hellenic Open University, 18 Parodos Aristotelous, 26335 Patras, Achaea, Greece 


\section{Introduction}

Over the past decades extensive research has been carried out in order to predict future returns of the Greek Stock Exchange. The latter offers various financing tools and solutions to companies, expands local and foreign investor choice by providing a safe, stable and easy environment in full alignment with international practices and the European regulatory framework. The Greek stock market offers some profitable industry sectors as options to invest in, such as tourism, energy, food \& beverage, the ICT sector, export-oriented manufacturing and logistics (Ghosh et al. 2021; Koutsokostas et al. 2019; Christopoulos et al. 2018). Through future valuation, investors attempt to determine the intrinsic value of each security in order to identify investment opportunities. If a market is efficient, the price of any security reflects all available company information and therefore its price should be equal to its intrinsic value. However, because markets are not always effective, the purpose of valuation is to identify overpriced and underpriced securities.

The aim of this study is to examine if the CAPE, the P/E and the P/BV ratios to forecast the future returns of the Greek Stock Market. We therefore investigate the role of the P/E and P/BV ratios in the Greek Stock Market, exploring whether the cyclical component of the price to book value and the price to earnings ratios contain a forecast power for stock returns. In addition, we inspect if Robert Shiller's cyclically adjusted price/earnings ratio (CAPE) is a powerful descriptor, as well as a useful predictor, of long-term equity returns in the Greek Stock Market. We have also tried to associate our CAPE ratio findings to the Efficient Market Hypothesis. There are many studies about other financial ratios for the Athens Stock Exchange (Drousia et al. 2019; Dokas et al. 2014; Papadaki and Siougle 2007; Christopoulos et al. 2019; Papathanasiou et al. 2019). To the best of our knowledge, a similar study concerning the CAPE ratio and the Greek Stock Market has not been conducted to this day, so this is the gap our study endeavors to fill.

For many decades, the CAPE ratio (Cyclically Adjusted Price to Earnings ratio) or Shiller's P/E ratio has been used by academics, researchers, investing firms and others in an attempt to evaluate the US Stock Market, especially the S\&P Index and many other stock markets globally. The supporters of the ratio believe that it can predict future returns (Angelini et al. 2012; Lleo and Ziemba 2019; Dimitrov and Jain 2018; Rangvid 2017).

For the purpose of our research, we use the FTSE/ASE Large Cap Stock Index established in September 1997, which consists of the 25 largest and most liquid stocks that trade on the Athens Stock Exchange. The period of the present analysis spans from the date the Index was established up to December 2018. Though this specific time span may in fact seem sufficient, it actually is not, as the CAPE index requires decades of earnings data in order to be calculated. For this reason, we have also created a variant of the index, the CAPE 5, which uses five-year earnings.

We focus on the Greek stock market due to the transformation taking place in Greece's economy following the country's recent financial crisis, as it was 
the weakest "peripheral" emerging market for a number of reasons (debt crisis, market capitalization slump, CDS spreads, the Brexit referendum, investor risk aversion, counterparty risk, market illiquidity, etc.). Today there seems to be a new focus on exports, innovation and more active trading in all ASE Stock Index Caps.

The research questions which this paper attempts to answer are the following: (a) Are Cyclically Adjusted Price to Earnings (CAPE) or Shiller's P/E ratio, along with $\mathrm{P} / \mathrm{E}$ and $\mathrm{P} / \mathrm{BV}$ capable of predicting future returns of the FTSE/ASE Large Cap Index? (b) Is the Greek Stock Market informationally efficient (EMH) for the time period examined? (c) Which ratio from the above mentioned has the most predictable power over the FTSE/ASE Large Cap Index for the period examined?

The predictive power of the CAPE ratio is tested by examining the relationship between the future returns of one, three, five and ten years of the FTSE/ ASE Large Cap Index and CAPE, CAPE 5, P/E and P/BV (Wu 2014; Rahman and Shamsuddin 2019; Ramcharran 2002; Koutsokostas et al. 2017). To examine these relationships, we construct several regression models, while in an effort to increase their interpretive ability, we add to some of them two additional variables: The returns of short- and long-term interest rates.

The CAPE or Shiller's $\mathrm{P} / \mathrm{E}$ is a valuation ratio that uses the average of real (inflation-adjusted) earnings over a period of ten years in order to smooth out the large fluctuations in earnings that arise during an economic cycle, causing the Price to Earnings ratio to instantly appear artificially inflated. Furthermore, the Price to Earnings ratio seems outrageously high for the time being, for the sole reason that SARS-CoV-2 (COVID-19) has temporarily shrunk earnings. Robert Shiller's ratio is arguably considered the gold standard for gauging if equities are undervalued or not. The name CAPE derives from the initials Cyclically Adjusted Price-to-Earnings ratio, and its second name from Robert J. Shiller, American Economist, Sterling Professor of Economics in Yale University and Nobel Laureate (2013). The biggest advantage of the CAPE ratio lies within its own calculation. Instead of using annual earnings (those that the P/E ratio uses), average tenyear earnings are used resulting in a more stable ratio. Annual earnings exhibit higher volatility, thus being "noisy", more so in times of economical crises, hence the P/E ratio is "noisy" too. On the other hand, the CAPE ratio appears smoother. Additionally, the fact that the CAPE ratio has been able to predict two forthcoming crises, i.e. the dot-com bubble (2002) and the housing bubble (2007-2009), has made it very attractive (Philips and Kobor 2020; Radha 2018; McMillan 2019; Samitas, et al. 2020).

This study contributes to the existing literature by investigating for the first time, to the best of our knowledge, Robert Shiller's Cyclically Adjusted Price/Earnings ratio (CAPE) as a useful predictor of equity returns in the Greek Stock Market. Furthermore, by adopting the CAPE ratio, the Greek Market will be in a position to forecast future returns. This study in particular is significant for three reasons: First of all, it focuses on a less developed and efficient stock market, given the existing paucity of research in such markets. Secondly, in contrast to prior relevant studies, it examines for the first time the CAPE ratio's predicting power in the Athens Stock Exchange. Finally, traders would benefit from this research, as they will find that this 
financial ratio works in the Athens Stock Exchange and that it is definitely profitable, since it has been tested with more advanced statistical methods.

So in this paper there will be an investigation of the time period from 1997 to 2018. This specific period is very important for the Athens Stock Exchange, as there are no prior studies for the examined ratio for the above mentioned period during which the Athens Stock exchange became a more developed market, Greece adopted the Euro currency and a successful derivatives market was introduced. Moreover, during this said period a series of political and economic events took place in Greece, i.e. the covered period; the Greek debt crisis; nine electoral contests; three memorandums and one referendum.

The structure of this chapter is organized as follows: The second section encompasses the literature review. The third section presents the data and methodological issues. The fourth section analyzes the empirical findings of the research. The final section contains the concluding remarks.

\section{Literature review}

Weigand and Irons (2007) investigated the market P/E and its relation to future stock returns, aggregate earnings and interest rates in the U.S. They used both the P/E and the CAPE ratio. Their results indicated that the relation between the above two ratios and future earnings and returns seems similar except when the P/E ratio is very high. The results of Aras and Yilmaz (2008) revealed that investors in emerging markets could be able to forecast future market stock returns with a high probability for a one-year period using the Book to Market ratio and partially the Dividend Yield. On the other hand, the $\mathrm{P} / \mathrm{E}$ ratio plays a minor role in predicting stock returns.

Davis et al. (2012) confirmed that valuation metrics such as Price to Earnings ratios have had an inverse or mean-reverting relationship with future stock market returns. They reached similar results having used either trailing twelve-month earnings or the cyclically adjusted earnings which are used in the calculation of the CAPE ratio. Klement (2012) examined if the CAPE ratio may be used as a forecasting and valuation tool for 35 countries, including emerging ones. His findings indicated that the CAPE is a reliable long-term valuation indicator for developed and emerging markets and so he used it to predict real future returns for each market over the following five years. Klement and Dettman (2014) examined the relationship between risk and return, concluding that on the basis of current valuation levels of the CAPE, the US market exhibits a high risk of significant future capital losses. Klement (2015) examined the relationship between returns of countries with different currencies and concluded that the difference among the CAPE values offer a sighting of the long run trends of exchange rates. Liem and Basana (2012) examined the relationship between the P/E ratio and the stock returns (increased liquidity) listed on the Indonesian Stock Exchange. They found that the six-month returns differ between low and high $\mathrm{P} / \mathrm{E}$ stocks, while for longer periods there is no difference in portfolio returns with various $\mathrm{P} / \mathrm{E}$ values.

Gray and Vogel (2013) tested the ability of various cyclically adjusted ratios to predict future returns, including a variation of the CAPE (10-year average of actual 
earnings to market capitalization), on NYSE, AMEX and NASDAQ stocks. Their results concluded that the CAPE did not perform the best, but the CA-BM (10-year average of real book value to market capitalization) was marginally better. Bunn and Shiller (2014) tested the predictive capability of the CAPE ratio in the Industrials, Utilities and Railroads sectors from 1870 until early 2013. They showed that the CAPE is not only effective in predicting how each sector performs, but it also has the ability to evaluate the performance across sectors. Keimling (2016) examined the predicting ability of CAPE in 17 MSCI Indices from 1979. In addition, for the same Indices, he examined the predicting ability of the P/E, the P/BV, and the PC (Price-to cash flow) ratios, the dividend yield and an adjusted for changes in payout ratios CAPE. The results of his research indicate that only the P/BV and the CAPE provide reliable forecasts of future returns and that in countries with structural breaks, the $\mathrm{P} / \mathrm{BV}$ is more reliable.

Philips and Ural (2016) tried to enhance the CAPE in order to confute the criticism it receives in being overly pessimistic, of lacking robustness to distortions in corporate earnings, and for overstating the long-term predictability of returns due to overlapping observations and endogeneity. They confirm that there are theoretical reasons which enable the CAPE to better predict future returns and that the use of historical earnings averages is shown to reduce their fluctuations, thus making the CAPE stronger than the P/E.

Jivraj and Shiller (2017) analyzed whether the CAPE is strong from three different aspects: They concluded that the CAPE and in particular the CAPE yield (1/ CAPE) is the most consistent estimator of future returns for both short and long term. Rangvid (2017) used the inverse ratio of the CAPE (1/CAPE) in order to convert it to a yield and use it for predicting the returns of the S\&P 500 for the next decade. He came to the conclusion that by using the combination of 1/CAPE and the total sum of future returns, the returns of the S\&P 500 for the next decade could be very well predicted. Dimitrov and Jain (2018) tested market efficiency using the CAPE index. They stated that stock returns are higher than US 10-year bond yields, so even at very high CAPE prices, the buy and hold strategy can work.

Lleo and Ziemba (2019) showed that both the P/E and the CAPE performed much better than the BSEYD (Bond-Stock Earnings Differential) on the Shanghai Stock Exchange, while all three ratios performed very well on the Shenzhen Stock Exchange. Kim and Byun (2018) showed that the CAPE exhibits a predictive power over the performance of the Equally Weighted (EW) and the Value Weighted (VW) CRSP Indices- predicting the performance of the EW Index better, even for future one-year returns. Angelini et al. (2012) concluded that 1/CAPE (the inverse ratio of the CAPE) remains a good benchmark for future long-term returns.

\section{Data and methodology}

\subsection{Data}

The period covered by this study is from the establishment of the FTSE/ASE Large cap, from September 1997 to December 2018. Data used for empirical analysis was 
collected from the Thompson Reuters Datastream database (closing prices of the Index as well as closing prices; EPS, BVS and Capitalization of each stock that comprised it); the Athens Stock Exchange Statistical Service (composition of the Index and investability weights of each stock) and the OECD database (prices of the 10-year Greek Government Bonds and the 3-month Treasury Bills).

Given that the EPS and BVS values are for each stock separately, the above data are calculated by comparing the percentages of each company in the Index per month in order to correctly calculate the total EPS and the BVS of the Index with the historical weighting. The Index's monthly closing prices and its monthly EPS are adjusted for inflation by base year 2018. Upon calculating the total EPS and the BVS of the Index, the following problem emerged: both the EPS and the BVS of the shares that participated in it over time exhibited negative values, which resulted in the Index itself exhibiting negative EPS and BVS, specifically in 2011, 2012, 2013, 2015 and 2016. Given these negative values, both the P/E and the P/BV of the Index could not be calculated since they do not exist as negative values. For this reason, all negative EPS and P/BV observations were excluded.

\subsection{Methodology}

The adjusted values of the Index are calculated by its logarithmic monthly real returns (adjusted for inflation) by formula (1), which are aggregated over time periods of one (1), three (3), five (5) and ten (10) years, creating the variables 1YR, $3 \mathrm{YR}, 5 \mathrm{YR}$ and 10YR, respectively.

$$
r_{t}=\ln \frac{P_{t}}{P_{t-1}}
$$

The P/E ratio of the FTSE/ASE Large Cap Index is then calculated by using Trailing 12 Months EPS (TTM). Finally, the CAPE ratio is calculated based on the Robert Shiller calculation and then the CAPE 5 ratio which is a variant of the CAPE ratio using five (5) years of EPS. For the calculations of the CAPE 5 and the CAPE indices, the following formulas 2 and 3 are used respectively:

$$
\begin{aligned}
& C A P E 5_{t}=\ln \frac{P_{t}}{\frac{1}{5}\left(E P S_{t-1}+E P S_{t-2}+\cdots+E P S_{t-5}\right)} \\
& C A P E_{t}=\ln \frac{P_{t}}{\frac{1}{10}\left(E P S_{t-1}+E P S_{t-2}+\cdots+E P S_{t-10}\right)}
\end{aligned}
$$

To examine the relationship between the performance of the FTSE/ASE Index Large Cap and the various factors, we defined as dependent the variables $1 \mathrm{YR}_{\mathrm{t}}+\mathrm{k}$ (1-year returns), $3 \mathrm{YR}_{\mathrm{t}}+\mathrm{k}$ (3-year returns), $5 \mathrm{YR}_{\mathrm{t}}+\mathrm{k}$ (5-year returns) and $10 \mathrm{YR}_{\mathrm{t}}+\mathrm{k}\left(10\right.$-year returns) and as independent the variables $\mathrm{P} / \mathrm{E}_{\mathrm{t}}$ (price to TTM earnings ratio), $\mathrm{CAPE}_{\mathrm{t}}$ (5-year average price to earnings ratio), $\mathrm{CAPE}_{\mathrm{t}}$ (10-year average price to earnings ratio-CAPE or Shiller's $\mathrm{P} / \mathrm{E}$ ), $\mathrm{P} / \mathrm{BV}_{\mathrm{t}}$ (price to the book 
value ratio), $\mathrm{RLR}_{\mathrm{t}}$ (returns of the 10-year Greek Government Bonds) and $\mathrm{RSR}_{\mathrm{t}}$ (returns of the 3-month Greek Treasury Bills).

We first examine the descriptive statistics of the variables. Then, we proceed to normality (using the Jarque-Bera statistic and the Shapiro-Wilk test), stationarity (using the Augmented Dickey-Fuller) and correlation (through Pearson correlation coefficient). We then construct several regression models in order to examine whether a relationship between our dependent and independent variables exists, but also to compare which relationships will emerge, also examining which factor proves to be the best estimator of future returns. Our regression models for each dependent variable are seven in number (28 in total) and their equations for $\mathrm{n}=1,3,5$ and 10 and for $\mathrm{k}=1,3,5,10$ are the following:

$$
\begin{gathered}
n Y R_{t+k}=a+\beta P E_{t}+\varepsilon_{t+k} \\
n Y R_{t+k}=a+\beta C A P E 5_{t}+\varepsilon_{t+k} \\
n Y R_{t+k}=a+\beta C A P E_{t}+\varepsilon_{t+k} \\
n Y R_{t+k}=a+\beta P B V_{t}+\varepsilon_{t+k} \\
n Y R_{t+k}=a+\beta_{1} P E_{t}+\beta_{2} R L R_{t}+\beta_{3} R S R_{t}+\beta_{4} P B V_{t}+\varepsilon_{t+k} \\
n Y R_{t+k}=a+\beta_{1} C A P E 5_{t}+\beta_{2} R L R_{t}+\beta_{3} R S R_{t}+\beta_{4} P B V_{t}+\varepsilon_{t+k} \\
n Y R_{t+k}=a+\beta_{1} C A P E_{t}+\beta_{2} R L R_{t}+\beta_{3} R S R_{t}+\beta_{4} P B V_{t}+\varepsilon_{t+k}
\end{gathered}
$$

After completing the regression process, we perform residual tests (normality, autocorrelation, heteroskedasticity and multicollinearity). In order to evaluate the results of the regressions, we set a threshold of $95 \%$ confidence interval $(p$-value $<0.05)$.

\section{Empirical results}

\subsection{Preliminary analysis}

Table 1 summarizes the descriptive statistics of the variables. We observe that most variables do not follow the normal distribution. Among the calculated ratios (P/E, CAPE5, CAPE and P/BV), P/E and P/BV ratios exhibit a high standard deviation, whilst the CAPE exhibits the lowest one. The high volatility of the P/E and P/BV indices is expected based on the literature (Davis et al. 2012), since the annual EPS used to calculate them is more volatile than the 5-year and 10-year normalized EPS of the CAPE 5 and CAPE, respectively. 


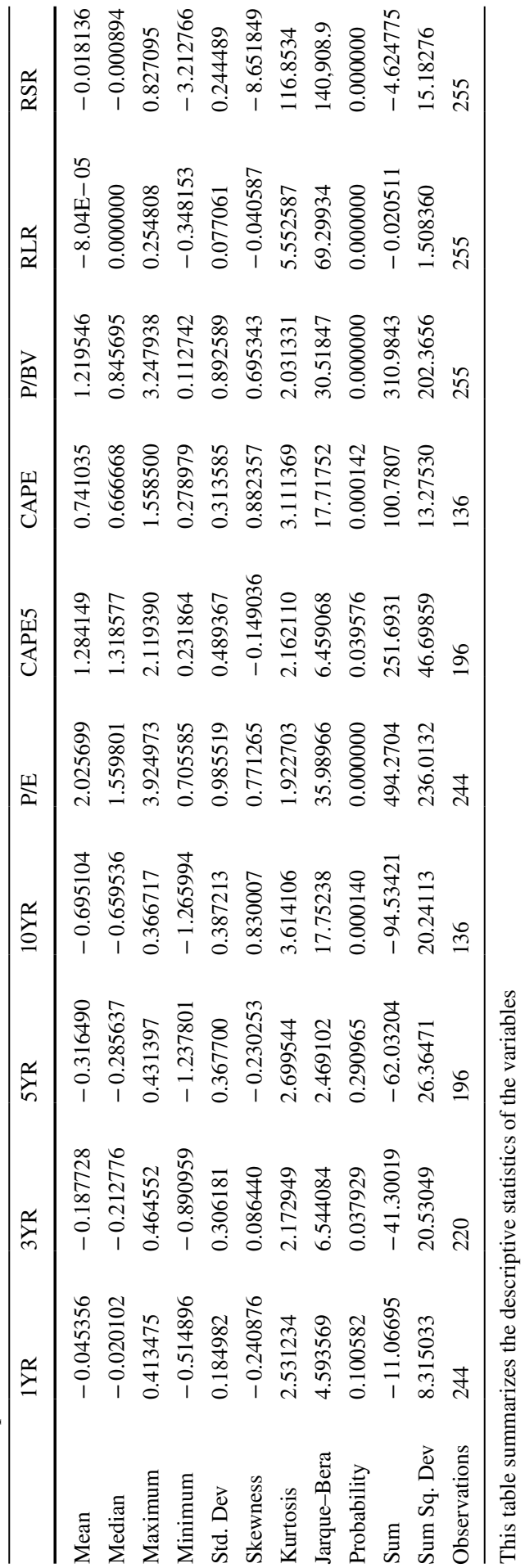




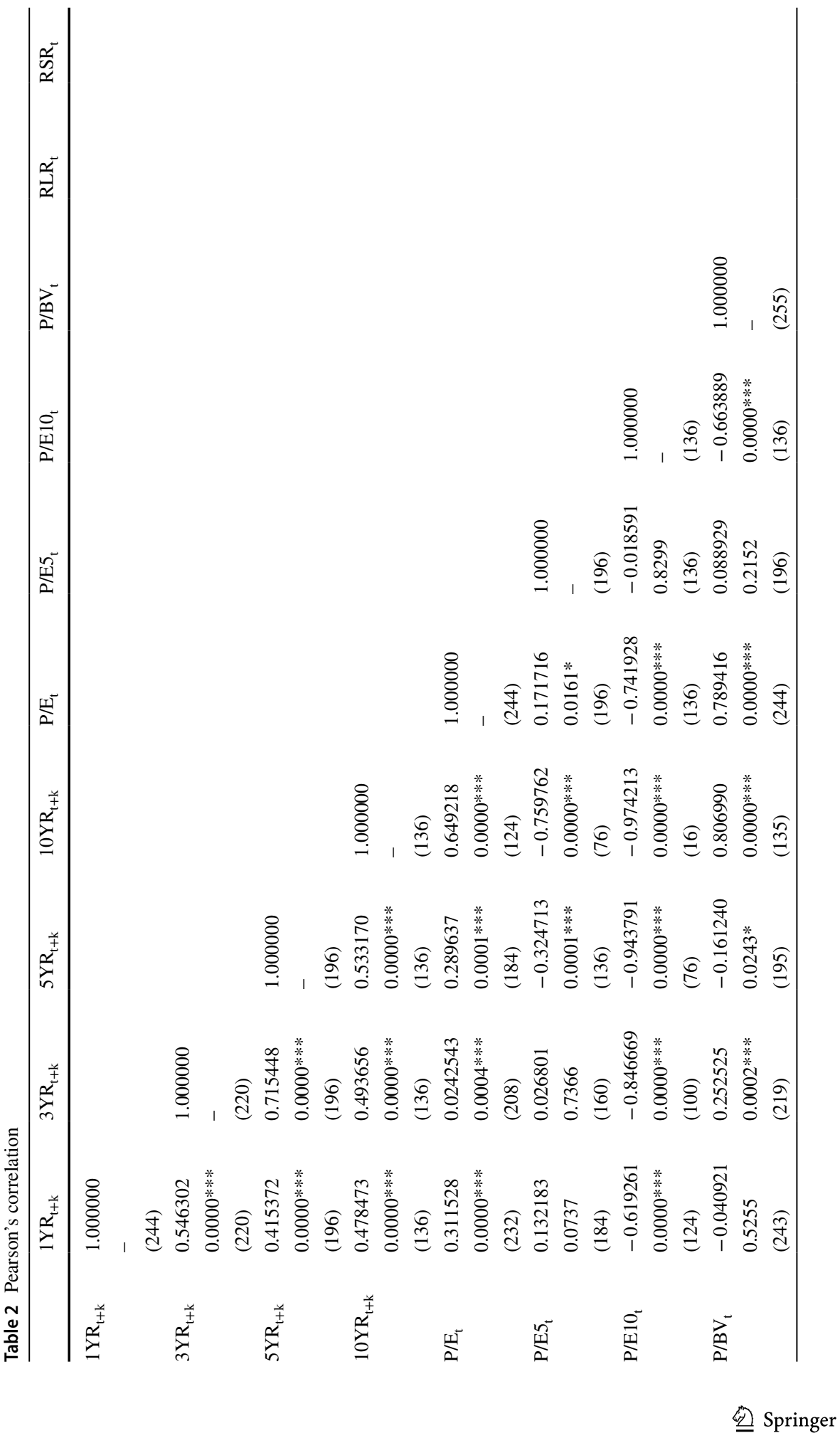




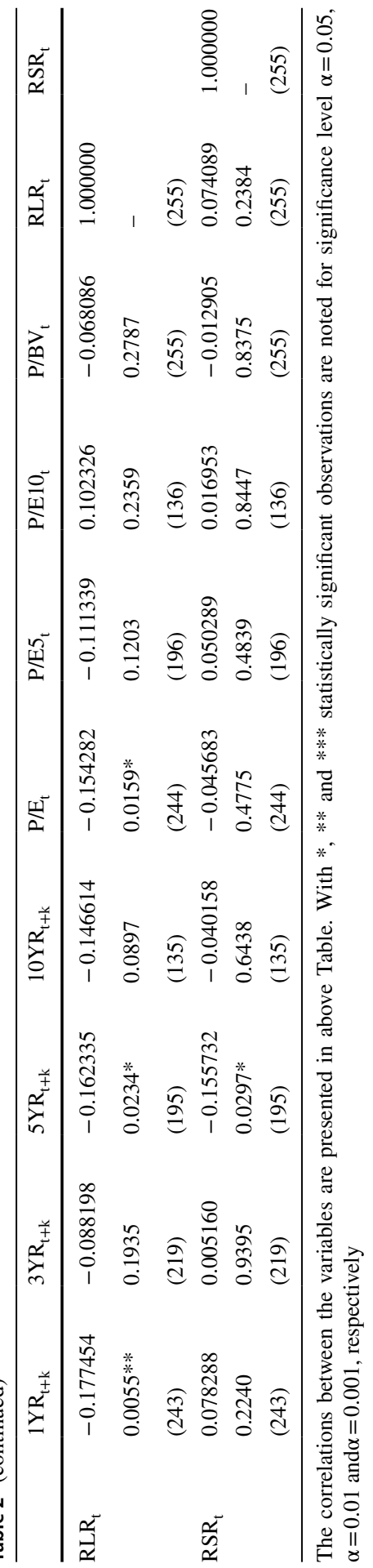


Table 3 Unit root test at levels (Augmented Dickey Fuller Test)

\begin{tabular}{llrll}
\hline Series & Prob & Lag & MaxLag & Obs \\
\hline 1YR & $0.0095^{* *}$ & 13 & 14 & 230 \\
3YR & 0.3286 & 0 & 14 & 219 \\
5YR & 0.6061 & 0 & 14 & 195 \\
10YR & 0.0835 & 0 & 12 & 135 \\
P/E & 0.5703 & 0 & 14 & 243 \\
CAPE5 & 0.9421 & 1 & 14 & 194 \\
CAPE & 0.0856 & 0 & 12 & 135 \\
P/BV & 0.3162 & 0 & 15 & 254 \\
RLR & $0.0000^{* * *}$ & 0 & 15 & 254 \\
RSR & $0.0000^{* * *}$ & 0 & 15 & 254 \\
\hline
\end{tabular}

ADF test in order to examine the stability of our variables is presented in above Table.With *,** and *** statistically significant observations are noted for significance level $\alpha=0.05, \alpha=0.01$ and $\alpha=0.001$, respectively. The lag order for each variable is selected according to the Schwarz Info Criterion

Table 4 Unit root test at first differences (Augmented Dickey Fuller Test)

\begin{tabular}{llcll}
\hline Series & Prob & Lag & MaxLag & Obs \\
\hline D(1YR) & $0.0000 * * *$ & 12 & 14 & 230 \\
D(3YR) & $0.0000 * * *$ & 0 & 14 & 218 \\
D(5YR) & $0.0000 * * *$ & 0 & 14 & 194 \\
D(10YR) & $0.0000 * * *$ & 0 & 12 & 134 \\
D(P/E) & $0.0000 * * *$ & 0 & 14 & 242 \\
D(CAPE5) & $0.0000 * * *$ & 0 & 14 & 194 \\
D(CAPE) & $0.0000 * * *$ & 0 & 12 & 134 \\
D(PBV) & $0.0000 * * *$ & 0 & 15 & 253 \\
D(RLR) & $0.0000 * * *$ & 3 & 15 & 250 \\
D(RSR) & $0.0000 * * *$ & 6 & 15 & 247 \\
\hline
\end{tabular}

ADF test in first differences in order to examine the stability of our variables is presented in above Table. With *, ** and *** statistically significant observations are noted for significance level $\alpha=0.05, \alpha=0.01$ and $\alpha=0.001$, respectively. The lag order for each variable is selected according to the Schwarz Info Criterion

The correlations between the variables are presented in Table 2. The P/E and $\mathrm{P} / \mathrm{BV}$ ratios are highly positive correlated (0.65 and 0.81 respectively), while the CAPE 5 and CAPE ratios exhibit a highly negative correlation $(-0.76$ and -0.97 ) with the 10-year yields. The CAPE ratio also exhibits a high negative correlation with the 3 -year and 5-year yields $(-0.85$ and -0.94 respectively). Longterm and short-term rate returns (RSR and RLR) exhibit a lower correlation with all the dependent variables. 
We then proceed with an ADF test to examine the stability of our variables (Table 3). The variables 1 YR, RLR and RSR are stationary, while the other variables are non-stationary, so we repeat the ADF test on the first differences, where all variables are stationary (Table 4). We then proceeded to use the Engle-Granger Test, including the relation between the Durbin-Watson statistic and the $\mathrm{R}^{2}$, thus examining if it would be possible to use our variables in levels. Unfortunately, in all our models the residuals were non-stationary, so we would be experiencing the phenomenon of a spurious regression. Had we been able to use our variables in levels, our results could have shown the long-term relationship between our dependent and independent variables. As Asteriou and Hall (2015) point out, by converting our variables into differences, our models will be incapable of producing a unique solution to the equation for their long-term relationship. Adjusting their example to our data, if our equation is $1 \mathrm{YR}=0.5 \mathrm{CAPE}$ and the CAPE has a value of 10 then the value of 1YR yields will be equal to 5. However, taking the first differences, 1YRt1YRt-1 =0.5 (CAPEt-CAPEt-1, even if we know that CAPE=10), we cannot solve the equation without knowing the past values of $1 \mathrm{YR}$ and the CAPE-and the solution for 1YR will not be unique.

\subsection{Regression analysis}

\subsubsection{Results}

Taking the literature (Jivraj and Shiller 2017) into consideration, we were aware that in our regression models we would face the following issues: (a) our variables are not all exogenous, considering that the price $\left(\mathrm{P}_{\mathrm{t}}\right)$ of the Index would appear on both sides of the equation violating the OLS assumptions and (b) the residuals would appear highly autocorrelated because of the presence of overlapping data.

The above could result in increased values of the $\mathrm{R}^{2}$ which could lead to an increased predictability than the actual one and biased t-statistic values, which in turn could lead us to reject the null hypothesis of the unpredictability of our regression models. For this reason, we used the Newey-West HAC (Heteroskedasticity and Autocorrelation Covariance) estimators, which are the ones most commonly used in empirical studies containing overlapping data (Harri and Brorsen 1998; Arnott et al. 2017) to estimate more accurately the errors in both autocorrelation and heteroskedasticity.

Before using the OLS method with the HAC estimators in our models, we examine if the residuals are autocorrelated (using Breusch-Godfrey LM test) and heteroscedastic (using a White test). Half of our models exhibited autocorrelation in their residuals, while only one exhibited heteroskedasticity.

Finally, we performed a Variance Inflation Factor (VIF) test to our multiple regression models for multicollinearity. Only one of them (model 4.3.b) had a VIF $>2.5$, so we rejected the independent variable RSR (which had an increased VIF value and was also not statistically significant in our model) in order to address the multicollinearity. 
Table 5 Results from simple and multiple regressions for dependent variable $1 \mathrm{YR}_{\mathrm{t}+\mathrm{k}}$

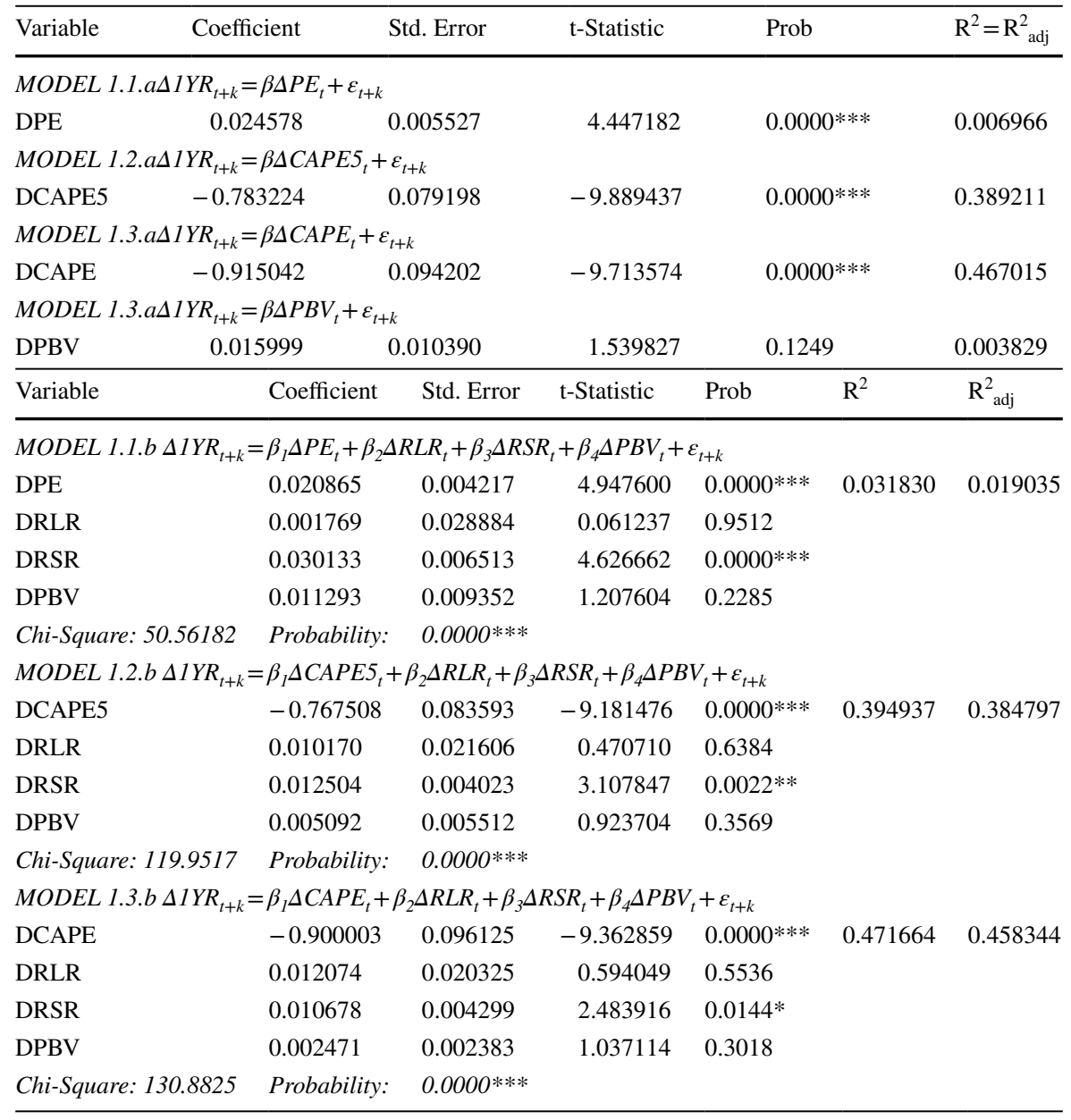

Results of our regression analysis for each dependent variable separately. With *, ** and *** statistically significant observations are noted for significance level $\alpha=0.05, \alpha=0.01$ and $\alpha=0.001$, respectively

Tables 5, 6, 7, 8 report the detailed results of our regression analysis for each dependent variable separately.

\subsubsection{Comparison of the models}

Table 9 presents the models demonstrating statistical significance classified by $\mathrm{R}^{2}$. The CAPE ratio appears to be a better estimator of future returns of the FTSE/ ASE Large Cap, as the models in the first six places include it as an independent variable. We can also observe that its predictability increases when the dependent variables are long-term (10YR, 5YR), while it decreases when they are short-term (3YR, 1YR). The CAPE 5 ratio follows, showing the same characteristics: it can 
Table 6 Results from simple and multiple regressions for dependent variable $3 \mathrm{YR}_{\mathrm{t}+\mathrm{k}}$

\begin{tabular}{|c|c|c|c|c|c|c|}
\hline Variable & Coefficient & Std. Error & t-Statistic & \multicolumn{2}{|l|}{ Prob } & $\mathrm{R}^{2}=\mathrm{R}_{\text {adj }}^{2}$ \\
\hline \multicolumn{7}{|c|}{ MODEL 2.1. $a \Delta 3 Y R_{t+k}=\beta \Delta P E_{t}+\varepsilon_{t+k}$} \\
\hline-0.00 & -0.008208 & 0.015859 & -0.517549 & \multicolumn{2}{|c|}{0.6053} & 0.000767 \\
\hline \multicolumn{7}{|c|}{ MODEL 2.2. $\alpha \Delta 3 Y R_{t+k}=\beta \Delta C A P E 5_{t}+\varepsilon_{t+k}$} \\
\hline DCAPE5 & -0.940039 & 0.100388 & -9.364069 & \multicolumn{2}{|c|}{$0.0000 * * *$} & 0.457788 \\
\hline \multicolumn{7}{|c|}{$M O D E L$ 2.3.a $\Delta 3 Y R_{t+k}=\beta \Delta C A P E 10_{t}+\varepsilon_{t+k}$} \\
\hline DCAPE & -1.056226 & 0.088820 & -11.89170 & \multicolumn{2}{|c|}{$0.0000 * * *$} & 0.593181 \\
\hline \multicolumn{7}{|c|}{$M O D E L$ 2.4.a $\Delta 3 Y R_{t+k}=\beta \Delta P B V_{t}+\varepsilon_{t+k}$} \\
\hline DPBV & 0.017815 & 0.015190 & 1.172840 & \multicolumn{2}{|c|}{0.2421} & 0.004182 \\
\hline Variable & Coefficient & Std. Error & t-Statistic & Prob & $\mathrm{R}^{2}$ & $\mathrm{R}^{2}$ adj \\
\hline \multicolumn{7}{|c|}{$M O D E L$ 2.1. $\beta \Delta 3 Y R_{t+k}=\beta_{1} \Delta P E_{t}+\beta_{2} \Delta R L R_{t}+\beta_{3} \Delta R S R_{t}+\beta_{4} \Delta P B V_{t}+\varepsilon_{t+k}$} \\
\hline DPE & -0.013493 & 0.012303 & -1.095632 & 0.2745 & 0.046303 & 0.032209 \\
\hline DRLR & -0.069695 & 0.042681 & -1.632947 & 0.1040 & & \\
\hline DRSR & 0.037840 & 0.005426 & 6.973995 & $0.0000 * * *$ & & \\
\hline DPBV & 0.015818 & 0.014888 & 1.062460 & 0.2893 & & \\
\hline Chi-Square: 52.91488 & Probability: & $0.0000 * * *$ & & & & \\
\hline \multicolumn{7}{|c|}{$M O D E L$ 2.2. $\beta \Delta 3 Y R_{t+k}=\beta_{1} \Delta C A P E 5_{t}+\beta_{2} \Delta R L R_{t}+\beta_{3} \Delta R S R_{t}+\beta_{4} \Delta P B V_{t}+\varepsilon_{t+k}$} \\
\hline DCAPE5 & -0.919549 & 0.105015 & -8.756326 & $0.0000 * * *$ & 0.472597 & 0.462389 \\
\hline DRLR & -0.064775 & 0.033623 & -1.926501 & 0.0559 & & \\
\hline DRSR & 0.014847 & 0.002450 & 6.060406 & $0.0000 * * *$ & & \\
\hline DPBV & 0.000917 & 0.011428 & 0.080229 & 0.9362 & & \\
\hline Chi-Square: 320.4180 & Probability: & $0.0000 * * *$ & & & & \\
\hline \multicolumn{7}{|c|}{$M O D E L$ 2.3. $\beta \Delta 3 Y R_{t+k}=\beta_{1} \Delta C A P E_{t}+\beta_{2} \Delta R L R_{t}+\beta_{3} \Delta R S R_{t}+\beta_{4} \Delta P B V_{t}+\varepsilon_{t+k}$} \\
\hline DCAPE & -1.035107 & 0.088279 & -11.72537 & $0.0000 * * *$ & 0.607497 & 0.595103 \\
\hline DRLR & -0.056716 & 0.032839 & -1.727081 & 0.0874 & & \\
\hline DRSR & 0.012657 & 0.001863 & 6.794665 & $0.0000 * * *$ & & \\
\hline DPBV & -0.000969 & 0.005878 & -0.164927 & 0.8694 & & \\
\hline F-Statistic 543.9501 & Probability: & $0.0000 * * *$ & & & & \\
\hline
\end{tabular}

Results of our regression analysis for each dependent variable separately. With *, ** and *** statistically significant observations are noted for significance level $\alpha=0.05, \alpha=0.01$ and $\alpha=0.001$, respectively

better explain long-term returns (10YR, 5YR) than short-term ones. In all the models however, the CAPE 5 and the CAPE ratio exhibit higher $\mathrm{R}^{2}$ than the $\mathrm{P} / \mathrm{E}$ and $\mathrm{P} /$ $\mathrm{BV}$ ratios. From the above data we conclude that both Cyclically Adjusted ratios are better estimators of long- and short-term returns.

The $\mathrm{P} / \mathrm{E}$ ratio appears to be important mainly in multiple regressions of shortterm returns and in simple regressions of one-year returns, but with a very low $\mathrm{R}^{2}$.

The P/BV index (as a standalone independent variable) does not appear at all in Table 9, since it was not statistically significant in any of the regression models and was not statistically significant in the multiple regression models either.

Short-term interest rate (RSR) returns are statistically significant in the one-, three-, and five-year models, appearing more significant in the $3 \mathrm{YR}$ models. 
Table 7 Results from simple and multiple regressions for dependent variable $5 \mathrm{YR}_{\mathrm{t}+\mathrm{k}}$

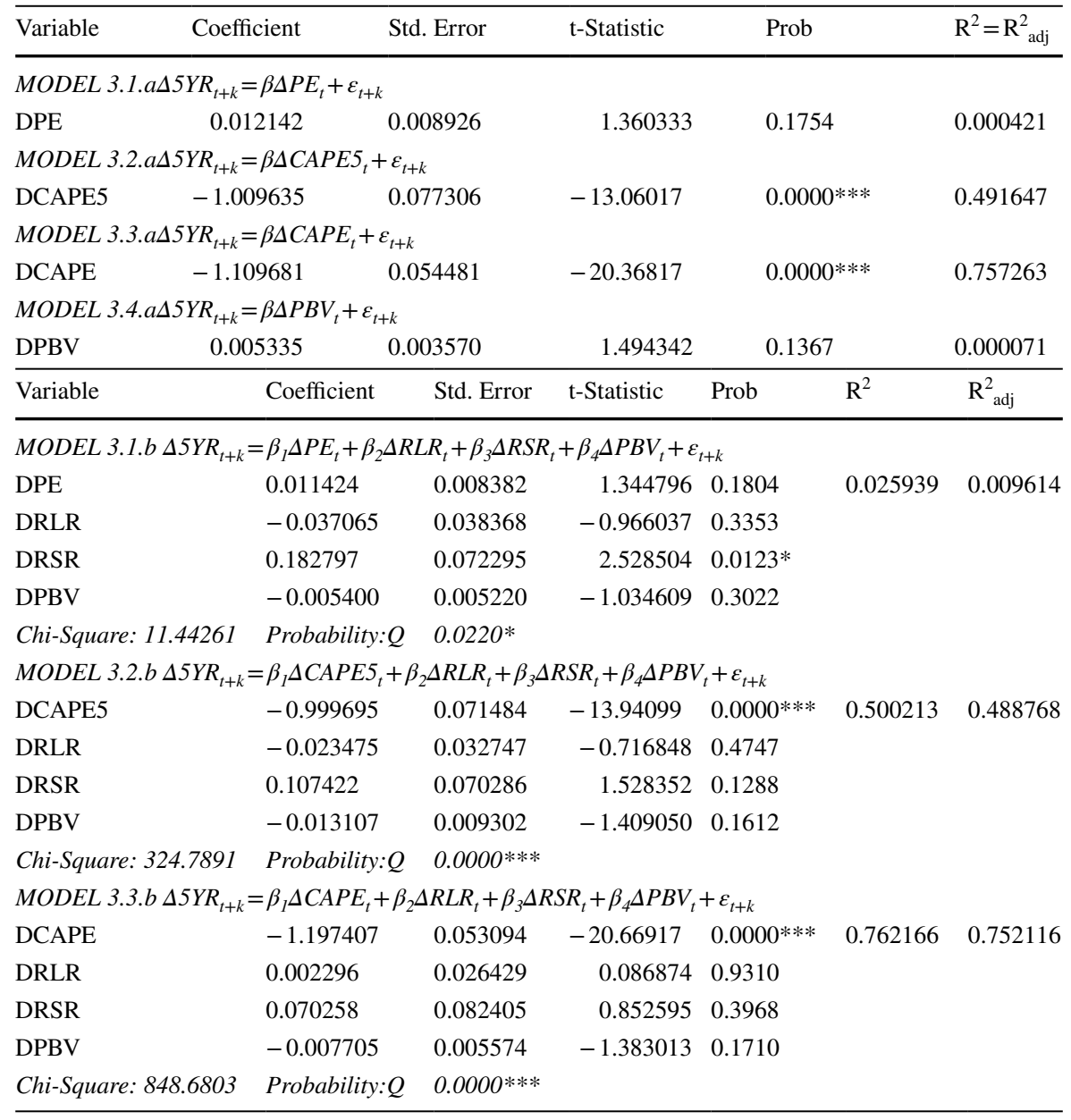

Results of our regression analysis for each dependent variable separately. With *, ** and *** statistically significant observations are noted for significance level $\alpha=0.05, \alpha=0.01$ and $\alpha=0.001$, respectively

Long-term interest rate returns (RLR) appear statistically significant only in the 10-year return model, which does include the independent variable CAPE.

Finally, Table 10 shows us the relationship between the CAPE and future 5 and 10 year returns. The results show that high ratio values are followed by low future returns and vice versa for the preceding five and ten years. Since our data start in 1997, we are unfortunately unable to compare the CAPE ratio values with its historical average before 2008 in order to predict the financial crisis in our country. However, its value in 2007 was very high (35.40), giving us some indication of its capability. 
Table 8 Results from simple and multiple regressions for dependent variable $10 \mathrm{YR}_{\mathrm{t}+\mathrm{k}}$

\begin{tabular}{|c|c|c|c|c|c|c|}
\hline Variable & Coefficient & Std. Error & t-Statistic & \multicolumn{2}{|l|}{ Prob } & $\mathrm{R}^{2}=\mathrm{R}_{\text {adj }}^{2}$ \\
\hline \multicolumn{7}{|c|}{ MODEL 4.1.a $10 Y R_{t+k}=\beta \Delta P E_{t}+\varepsilon_{t+k}$} \\
\hline DPE & 0.003276 & 0.063841 & 0.051317 & \multicolumn{2}{|c|}{0.9592} & -0.011106 \\
\hline \multicolumn{7}{|c|}{ MODEL 4.2.a $10 Y R_{t+k}=\beta \Delta C A P E 5_{t}+\varepsilon_{t+k}$} \\
\hline DCAPE5 & -0.950251 & 0.148615 & -6.394067 & \multicolumn{2}{|c|}{$0.0000 * * *$} & 0.487162 \\
\hline \multicolumn{7}{|c|}{$M O D E L$ 4.3. $a \Delta 10 Y R_{t+k}=\beta \Delta C A P E_{t}+\varepsilon_{t+k}$} \\
\hline DCAPE & -0.767214 & 0.037095 & -20.68265 & \multicolumn{2}{|c|}{$0.0000 * * *$} & 0.633051 \\
\hline \multicolumn{7}{|c|}{ MODEL 4.4.as $10 Y R_{t+k}=\beta \Delta P B V_{t}+\varepsilon_{t+k}$} \\
\hline DPBV & 0.080575 & 71992 & 1.119215 & \multicolumn{2}{|c|}{0.2651} & -0.009824 \\
\hline Variable & Coefficient & Std. Error & t-Statistic & Prob & $\mathrm{R}^{2}$ & $\mathrm{R}_{\text {adj }}^{2}$ \\
\hline \multicolumn{7}{|c|}{ MODEL 4.1.b $\Delta 10 Y R_{t+k}=\beta_{1} \Delta P E_{t}+\beta_{2} \Delta R L R_{t}+\beta_{3} \Delta R S R_{t}+\beta_{4} \Delta P B V_{t}+\varepsilon_{t+k}$} \\
\hline DPE & -0.046505 & 0.685557 & -0.678345 & 0.4989 & 0.008727 & -0.016263 \\
\hline DRLR & 0.024188 & 0.116236 & 0.208092 & 0.8355 & & \\
\hline DRSR & -0.154896 & 0.255646 & -0.605902 & 0.5457 & & \\
\hline DPBV & 0.122271 & 0.073155 & 1.671392 & 0.0973 & & \\
\hline Chi-Square: 3.559664 & Probability: $Q$ & 0.4689 & & & & \\
\hline \multicolumn{7}{|c|}{ MODEL 4.2.b $\Delta 10 Y R_{t+k}=\beta_{1} \Delta C A P E 5_{t}+\beta_{2} \Delta R L R_{t}+\beta_{3} \Delta R S R_{t}+\beta_{4} \Delta P B V_{t}+\varepsilon_{t+k}$} \\
\hline DCAPE5 & -0.949213 & 0.146790 & -6.466449 & $0.0000 * * *$ & 0.493599 & 0.472201 \\
\hline DRLR & -0.070379 & 0.135900 & -0.517871 & 0.6062 & & \\
\hline DRSR & -0.046350 & 0.136139 & -0.340459 & 0.7345 & & \\
\hline DPBV & 0.046688 & 0.124155 & 0.376046 & 0.7080 & & \\
\hline Chi-Square: 104.2760 & Probability: & $0.0000 * * *$ & & & & \\
\hline \multicolumn{7}{|c|}{$M O D E L$ 4.3.b $\Delta 10 Y R_{t+k}=a+\beta_{1} \Delta C A P E_{t}+\beta_{2} \Delta R L R_{t}+\beta_{3} \Delta P B V_{t}+\varepsilon_{t+k}$} \\
\hline DCAPE & -0.793539 & 0.039976 & -19.85047 & $0.0000 * * *$ & 0.739026 & 0.695531 \\
\hline DRLR & -0.341655 & 0.075362 & -4.533518 & $0.0007 * * *$ & & \\
\hline DPBV & 0.126398 & 0.120874 & 1.045697 & 0.3163 & & \\
\hline Chi-Square: 494.1461 & Probability: & $0.0000 * * *$ & & & & \\
\hline
\end{tabular}

Results of our regression analysis for each dependent variable separately. With *, ** and *** statistically significant observations are noted for significance level $\alpha=0.05, \alpha=0.01$ and $\alpha=0.001$, respectively

\section{Concluding remarks}

Based on our empirical analysis, the CAPE ratio appears to be a good estimator of future returns of the FTSE/ASE Large Cap Index. This is consistent with the results of other relevant studies such as those by Campbell and Shiller (1988), Davis et al. (2012), Bunn and Shiller (2014), Philips and Ural (2016), Klement (2012), Keimling (2016), Arnott et al. (2018) in other stock markets. Although the time span of the data is short (the FTSE/ASE Large Cap Index was established in 1997) in comparison to the data span of similar surveys, especially those for the S\&P 500 Index which dates back to 1900, our results seem encouraging. 
Table 9 Regression models—ranked by $\mathrm{R}^{2}$

\begin{tabular}{|c|c|c|}
\hline & Regression model & $\mathrm{R}^{2}\left(\mathrm{R}_{\text {adj }}^{2}\right)$ \\
\hline$(3.3 . b)$ & $\Delta 5 Y R_{t+k}=\Delta C A P E_{t}+\Delta R L R_{t}+\Delta R S R_{t}+\Delta P B V_{t}+\varepsilon_{t+k}$ & $0.762166(0.752116)$ \\
\hline$(3.3 . \mathrm{a})$ & $\Delta 5 Y R_{t+k}=\Delta C A P E_{t}+\varepsilon_{t+k}$ & 0.757263 \\
\hline$(4.3 . b)$ & $\Delta 10 Y R_{t+k}=\Delta C A P E_{t}+\Delta R L R_{t}+\Delta R S R_{t}+\Delta P B V_{t}+\varepsilon_{t+k}$ & $0.739026(0.695531)$ \\
\hline$(4.3 . a)$ & $\Delta 10 Y R_{t+k}=\Delta C A P E_{t}+\varepsilon_{t+k}$ & 0.633051 \\
\hline$(2.3 . b)$ & $\Delta 3 Y R_{t+k}=\Delta C A P E_{t}+\Delta R L R_{t}+\Delta R S R_{t}+\Delta P B V_{t}+\varepsilon_{t+k}$ & $0.607497(0.595103)$ \\
\hline$(2.3 . \mathrm{a})$ & $\Delta 3 Y R_{t+k}=\Delta C A P E_{t}+\varepsilon_{t+k}$ & 0.593181 \\
\hline$(3.2 . b)$ & $\Delta 5 Y R_{t+k}=\Delta C A P E 5_{t}+\Delta R L R_{t}+\Delta R S R_{t}+\Delta P B V_{t}+\varepsilon_{t+k}$ & $0.500213(0.488768)$ \\
\hline$(4.2 . b)$ & $\Delta 10 Y R_{t+k}=\Delta C A P E 5_{t}+\Delta R L R_{t}+\Delta R S R_{t}+\Delta P B V_{t}+\varepsilon_{t+k}$ & $0.493599(0.472201)$ \\
\hline (3.2.a) & $\Delta 5 Y R_{t+k}=\Delta C A P E 5_{t}+\varepsilon_{t+k}$ & 0.491647 \\
\hline$(4.2 . a)$ & $\Delta 10 Y R_{t+k}=\Delta C A P E 5_{t}+\varepsilon_{t+k}$ & 0.487162 \\
\hline$(2.2 . b)$ & $\Delta 3 Y R_{t+k}=\Delta C A P E 5_{t}+\Delta R L R_{t}+\Delta R S R_{t}+\Delta P B V_{t}+\varepsilon_{t+k}$ & $0.472597(0.462389)$ \\
\hline$(1.3 . b)$ & $\Delta I Y R_{t+k}=\Delta C A P E_{t}+\Delta R L R_{t}+\Delta R S R_{t}+\Delta P B V_{t}+\varepsilon_{t+k}$ & $0.471664(0.458344)$ \\
\hline (1.3.a) & $\Delta I Y R_{t+k}=\Delta C A P E_{t}+\varepsilon_{t+k}$ & 0.467015 \\
\hline$(2.2 . \mathrm{a})$ & $\Delta 3 Y R_{t+k}=\Delta C A P E 5_{t}+\varepsilon_{t+k}$ & 0.457788 \\
\hline$(1.2 . b)$ & $\Delta I Y R_{t+k}=\Delta C A P E 5_{t}+\Delta R L R_{t}+\Delta R S R_{t}+\Delta P B V_{t}+\varepsilon_{t+k}$ & $0.394937(0.384797)$ \\
\hline$(1.2 . \mathrm{a})$ & $\Delta I Y R_{t+k}=\Delta C A P E 5_{t}+\varepsilon_{t+k}$ & 0.389211 \\
\hline (2.1.b) & $\Delta 3 Y R_{t+k}=\Delta P / E_{t}+\Delta R L R,+\Delta R S R_{t}+\Delta P B V_{t}+\varepsilon_{t+k}$ & $0.046303(0.032209)$ \\
\hline$(1.1 . b)$ & $\Delta I Y R_{t+k}=\Delta P / E_{t}+\Delta R L R,+\Delta R S R_{t}+\Delta P B V_{t}+\varepsilon_{t+k}$ & $0.031830(0.019035)$ \\
\hline (3.1.b) & $\Delta 5 Y R_{t+k}=\Delta P / E_{t}+\Delta R L R_{t}+\Delta R S R_{t}+\Delta P B V_{t}+\varepsilon_{t+k}$ & $0.025939(0.009614)$ \\
\hline$(1.1 . a)$ & $\Delta 1 Y R_{t+k}=\Delta P / E_{t}+\varepsilon_{t+k}$ & 0.006966 \\
\hline
\end{tabular}

Table 10 The CAPE and future 5 and 10 year returns

\begin{tabular}{lccc}
\hline & CAPE $_{\mathrm{t}}$ & $5 \mathrm{YR}_{\mathrm{t}+\mathrm{k}}$ & $10 \mathrm{YR}_{\mathrm{t}+\mathrm{k}}$ \\
\hline 2007 & 35.40 & -1.06 & -1.17 \\
2008 & 21.26 & -0.79 & -1.00 \\
2009 & 10.97 & -0.50 & \\
2010 & 8.09 & -0.58 & \\
2011 & 5.43 & -0.49 & \\
2012 & 2.79 & -0.11 & \\
2013 & 3.70 & -0.21 & \\
\hline
\end{tabular}

The relationship between the CAPE and future 5 and 10 year returns

The relationship between the CAPE and future returns appears inversely proportional, that is, the higher the ratio, the lower the expected future returns. This inverse relationship is confirmed by the existing literature.

The biggest problem we faced in our econometric analysis, apart from the short time span of the data, was the non-stationarity of some variables. If all variables were stationary, we would have been in a position to evaluate the long-term relationship between them, but unfortunately this cannot be done, hence our conclusions apply only in the short term. Therefore, if we want to analyze the equation 
of model 3.3.b which is the most statistically important one, we can predict that a $10 \%$ increase in the FTSE/ASE CAPE ratio will cause a decrease in the future 5-year returns about $11 \%$.

$\mathrm{P} / \mathrm{E}$ ratio does not appear to have a predicting ability since it was statistically significant only in future one-year returns with a very low $\mathrm{R}^{2}$, confirming the previous studies of Aras \& Yilmaz (2008), and Liem \& Basana (2012). The P/BV ratio did not appear in a position to predict future returns, as it was not statistically significant in any of the models, which is opposing to the literature, since in many empirical studies the $\mathrm{P} / \mathrm{BV}$ ratio appears to be a better estimator of future returns than the CAPE ratio (Keimling 2016).

Short-term interest rate returns (RSR) are statistically significant in the one-, three-, and five-year models. Based on the t-stat their ability of predicting future returns appears better in three-year returns and it remains the same if the model includes the P/E, the CAPE 5 or the CAPE. Increasing short-term returns leads to higher returns in the future. Long-term interest rate returns (RLR) are statistically significant only in model 4.3.b, in which they appear to be inversely related to future ten-year returns, but cannot predict future returns sufficiently since their t-stat value is very low. This probably happened because the Athens Stock Exchange seems to exhibit different characteristics from those observed in very developed capital markets, such us low market capitalization, market thinness, non-synchronous trading, tend to react slowly and gradually to new information and low substantial fundraising.

In conclusion, the FTSE/ASE Large CAPE ratio and its variation the CAPE 5, which use five-year real earnings, are efficient estimators of future returns. Our findings are in line with Lleo \& Ziemba (2019) and Angelini et al., (2012). In addition, our empirical findings are compatible with the findings of Dimitrov \& Jain (2018) and Rangvid (2017).

The limitation of the research is that the CAPE ratio is inherently backwardlooking, rather than forward-looking. Another issue is that the ratio relies on GAAP earnings, which have undergone marked changes in recent years.

Our findings are inconsistent with the Efficient Market Hypothesis (EMH). When a market is efficient, both the variables we examined in our research and any other variables cannot predict future returns. As Robert Shiller (1996) himself points out about the relationship between the CAPE index and future returns "...but the strength of the association seems so strong as to suggest that this relation is not consistent with the efficient markets or random walk model".

The present study may have important implications for various market participants. Investors and portfolio managers make the most of the inferences regarding the usage of the $\mathrm{P} / \mathrm{E}$, the $\mathrm{P} / \mathrm{BV}$, the CAPE and the CAPE 5 ratios. At the same time, investors are urged to use the CAPE and the CAPE 5 ratios in order to maximize their forecasting ability. Finally, future research might have to consider whether an investor using this information, the CAPE ratio predicting capability, could achieve returns above average over time, given that the Greek stock market is not an efficient market. 


\section{References}

Angelini N, Bormetti G, Marmi S, Nardini F (2012) Value matters: predictability of stock index returns. SSRN Electron J. https://doi.org/10.2139/ssrn.2031406

Aras G, Yilmaz MK (2008) Price-earnings ratio, dividend yield, and market-to-book ratio to predict return on stock market: evidence from the emerging markets. J Glob Bus Technol 4(1):18-30

Arnott R, Chaves D, Chow T (2017) King of the Mountain: the Shiller P/E and macroeconomic conditions. J Portfolio Manag 44(1):55-68

Arnott R, Kalesnik V, Masturzo V (2018) CAPE fear: why CAPE Naysayers are wrong. Research affiliates article. https://www.researchaffiliates.com/en_us/publications/articles/645-cape-fearwhy-cape-naysayers-are-wrong.html. Accessed 20 Mar 2019

Asteriou D, Hall GS (2015) Applied econometrics. Red Globe Press

Bunn O, Shiller R, (2014) Changing times, changing values: a historical analysis of sectors within the US stock market 1872-2013. NBER Working Paper No. 20370 https://www.nber.org/papers/ w20370. Accessed 10 Sept, 2018

Campbell J, Shiller R (1988) Stock prices, earnings, and expected dividends. J Financ 43(3):661-676

Campbell J, Shiller R (1998) Valuation ratios and the long-run stock market outlook. J Portfolio Manag 24(2):11-26

Christopoulos A, Dokas I, Kollias I, Leventides J (2018) An implementation of soft set theory in the variables selection process for corporate failure prediction models: evidence from NASDAQ listed firms. Bull Appl Econ 6(1):1-20

Christopoulos A, Dokas I, Kalantonis P, Koukkou T (2019) Investigation of financial distress with a dynamic logit based on the linkage between liquidity and profitability status of listed firms. J Oper Res Soc 70(10):1817-1829

Davis J, Aliaga-Diaz R, Thomas CJ (2012) Forecasting stock returns: what signals matter, and what do they say now? The Vanguard Group. https://fairwaywealth.com/wp-content/uploads/Vangu ard-Research-11-30-2014.pdf. Accessed 18 Mar 2019

Dimitrov V, Jain P (2018) Shiller's CAPE: market efficiency and risk. Financ Rev 53(4):41-771. https://doi.org/10.2139/ssrn.2088140

Dokas I, Giokas D, Tsamis A (2014) Liquidity efficiency in the Greek listed firms: a financial ratio based on data envelopment analysis. Int J Corp Financ Account 1(1):40-59. https://doi.org/10. 4018/ijcfa.2014010103

Drousia A, Episcopos A, Leledakis G (2019) Market reaction to actual daily share repurchases in Greece. Quarter Rev Econ Financ 74:267-277. https://doi.org/10.1016/j.qref.2019.01.007

Fama EF, French KR (1988) Dividend yields and expected stock returns. J Financ Econ 22(1):3-25

Ghosh B, Papathanasiou S, Ramchandani N, Kenourgios D (2021) Diagnosis and prediction of IIGPS' countries bubble crashes during BREXIT". Mathematics 9(9):1003. https://doi.org/10.3390/ math9091003

Gray WR, Vogel J (2013) On the performance of cyclically adjusted valuation measures. SSRN Electron J. https://doi.org/10.2139/ssrn.2329948

Harri A, Brorsen BW (1998) The overlapping data problem. SSRN Electron J. https://doi.org/10. 2139/ssrn.76460

Jivraj F, Shiller G (2017) The many colours of CAPE. SSRN Electron J. https://doi.org/10.2139/ssrn. 3258404

Keimling N (2016) Predicting stock market returns using the Shiller CAPE: an improvement towards traditional value indicators? SSRN Electron J. https://doi.org/10.2139/ssrn.2736423

Kim K, Byun J (2018) Stock return predictability and seasonality. SSRN Electron J. https://doi.org/10. 2139/ssrn.3180992

Klement J, (2012) Does the Shiller-PE Work in Emerging Markets? SSRN Electron J. https://papers. ssrn.com/sol3/papers.cfm?abstract_id=2088140. Accessed 12 Sept, 2018

Klement J (2015) CAPE around the World update 2015: return differences and exchange rate movements. SSRN Electron J. https://doi.org/10.2139/ssrn.2626725

Klement J, Dettmann O (2014) Cape around the world: update 2014: the relationship between risk and return. SSRN Electron J. https://doi.org/10.2139/ssrn.2470935

Koutsokostas D, Papathanasiou S (2017) Mutual funds in Greece: case study of domestic equity mutual funds during financial crisis. Manag Financ 43(7):812-827. https://doi.org/10.1108/ MF-10-2016-0293 
Koutsokostas D, Papathanasiou S, Balios D (2019) Adjusting for risk factors in mutual fund performance and performance persistence. J Risk Financ 20(4):352-369. https://doi.org/10.1108/ JRF-07-2018-0108

Liem PF, Basana SR (2012) Price earnings ratio and stock return analysis evidence from liquidity 45 stocks listed in indonesia stock exchange. J Manajemendan Kewirausahaan. 14(1):7-12

Lleo S, Ziemba WT (2019) A tale of two indexes: predicting equity market downturns in China. SSRN Electron J. https://doi.org/10.2139/ssrn.2698422

Malkiel BG (2003) The efficient market hypothesis and its critics. J Econ Persp 17(1):9-82

McMillan DG (2019) Stock return predictability: using the cyclical component of the price ratio. Res Int Bus Financ 48:228-242. https://doi.org/10.1016/j.ribaf.2018.12.014

Papadaki A, Siougle G (2007) Value relevance of price, earnings and book values in the Athens Stock Exchange. Manag Financ 33(5):309-320. https://doi.org/10.1108/03074350710739597

Papathanasiou S, Koutsokostas D, Balios D, Eriotis N (2019) Winemaking Sector in Greece: an accounting-based approach. Int J Corp Financ Account 6(2):1-17. https://doi.org/10.4018/IJCFA.20190 70101

Philips T, Kobor A (2020) Ultra-simple Shiller's CAPE: how one year's data can predict equity market returns better than ten. J Portfolio Manag 46(4):140-155. https://doi.org/10.3905/jpm.2020.1.124

Philips TK, Ural C (2016) Uncloaking Campbell and Shiller's CAPE: a comprehensive guide to its construction and use. J Portfolio Manag 43(1):109-125

Radha SS (2018) A prognostic yield measure for country selection in the medium term using Shiller's PE. J Index Inv Summer 9(1):49-65. https://doi.org/10.3905/jii.2018.1.060

Rahman ML, Shamsuddin A (2019) Investor sentiment and the price-earnings ratio in the G7 stock markets. Pac Basin Financ J 55:46-62. https://doi.org/10.1016/j.pacfin.2019.03.003

Ramcharran H (2002) An empirical analysis of the determinants of the P/E ratio in emerging markets. Emerg Mark Rev 3(2):165-178. https://doi.org/10.1016/S1566-0141(02)00004-3

Rangvid J (2017) What rate of return can we expect over the next decade? Copenhagen Business School. https://rangvid.com/onewebmedia/What $\% 20$ rate $\% 20$ of $\% 20$ return $\% 20$ can $\% 20 \mathrm{we} \% 20$ expect $\%$ 20over\%20the\%20next\%20decade.\%20March\%202017.pdf. Accessed 18 Mar 2019

Samitas A, Kampouris E, Kenourgios D (2020) Machine learning as an early warning system to predict financial crisis. Int Rev Financ Anal 71:101507

Shiller R (1996) Price-earnings ratios as forecasters of returns: the stock market outlook in 1996. Yale University. http://www.econ.yale.edu// shiller/data/peratio.html. Accessed 18 Mar 2019

Siegel J (2016) The Shiller CAPE Ratio: a new look. Financ Anal J 72(3):41-50. https://doi.org/10.2469/ faj.v72.n3.1

Weigand R, Irons R (2007) The market P/E ratio, earnings trends, and stock return forecasts. J Portfolio Manag 33(4):87-101

Wu WT (2014) The forward E/P ratio and earnings growth. Adv Account 30(1):128-142. https://doi.org/ 10.1016/j.adiac.2014.04.002

Publisher's Note Springer Nature remains neutral with regard to jurisdictional claims in published maps and institutional affiliations. 